\title{
ENDURANCE-TRAINING INDUCED CHANGES IN SKELETAL MUSCLE PHOSPHOGLYCERATE KINASE OF OLD WISTAR RATS
}

\author{
JIAN Q. ZHOU, TIMOTHY P. WHITE ${ }^{a}$ and ARI GAFNI ${ }^{b}$ \\ Institute of Gerontology and Departments of Kinesiology" and Biological Chemistry ${ }^{b}$. The University of \\ Michigan, Ann Arbor, MI 48109 (U.S.A.)
}

(Received July 2nd, 1990)

(Revision received September 26th, 1990)

\section{SUMMARY}

Sufficiently intense, long-term, endurance training has been shown in several studies to induce a variety of adaptations in skeletal muscle, including a substantial restoration of the activities of several muscle enzymes which are known to be modified during biological aging. This activity-restoration may reflect either an increase in the amounts of enzyme proteins or an enhancement of the specific activities of these molecules. The present study examined the effect of long-term endurance training on the status of phosphoglycerate kinase in skeletal muscle of old rats, as compared with the enzyme isolated either from non-trained old or young animals. The kinetics of heat inactivation, which differ markedly between young and old forms of phosphoglycerate kinase, were used as a sensitive probe for the status of the enzyme. The results reveal a remarkable similarity between the heat inactivation patterns of phosphoglycerate kinase from the muscle of old, exercise-trained rats and enzyme purified from young animals, while enzyme samples isolated from sedentary old animals are significantly more heat-stable. Adaptation to endurance-training is thus evident at the molecular level, and maintains phosphoglycerate kinase in its young form. The aging of this enzyme has been previously shown to involve only conformational changes, which develop following a reversible partial oxidation of reactive cysteine residues. Whether the adaptation of the enzyme to endurancetraining results from enhancement in its turnover rate (i.e., dwell time in the cell becoming too short for modifications to develop) or is due to increased protection against oxidation (being the first step in the enzyme's aging) remains to be studied.

Key words: Exertion; Physical training; Aging; Enzyme aging; Enzyme folding

Correspondence to: Ari Gafni, Department of Biological Chemistry, The University of Michigan, Ann Arbor, MI 48109, U.S.A. 


\section{INTRODUCTION}

Phosphoglycerate kinase (PGK) is one of several glycolytic enzymes which have been shown to become modified in the tissues of old animals [1-3]. In particular, a marked age-related increase was found in the heat stability of PGK isolated from rat skeletal muscle [4], liver [5], brain [6] and cardiac tissue [7]. This modification is relatively easy to detect and follow in heat-inactivation experiments, and therefore presents a convenient way to monitor the enzyme status. Based on a large body of work that failed to reveal covalent modifications in PGK isolated from tissues of old animals, Rothstein [2] concluded that the structural modifications in this enzyme are purely conformational. This hypothesis has been recently tested and confirmed in experiments where samples of PGK from young and old rats were unfolded-refolded. In both skeletal and cardiac tissue the old form of the enzyme was shown to become fully rejuvenated [7,8]. Based on these experiments a two-step model for PGK aging was proposed in which an initial, reversible, oxidation of reactive cysteines leads to conformational changes that persist even after the enzyme is reduced and reactivated. Such oxidation-reduction protocol was indeed shown to convert young PGK in vitro to its conformationally modified old form. More recently Cook and Gafni have demonstrated that the young form of rat skeletal muscle PGK can be protected against this in vitro aging by a partial methylation of the highly reactive cysteine residues of the enzyme - a procedure which does not modify the enzymatic activity [9].

Endurance training of sufficient intensity, duration and frequency induces adaptations in skeletal muscle [10]. The principal adaptations result in an increased capacity to oxidize substrates, to conserve carbohydrates and to delay metabolic acidosis during long duration exercise [11]. Sanchez et al. found that the activities of several muscle enzymes which decline with age in rats may be significantly increased in old animals by endurance-training [12]. In contrast, the effects of endurance training on the activities of the same enzymes in muscles of young rats were modest. Baldwin et al. have similarly found that, with the exception of an increase in hexokinase in red muscle, the adaptive changes in the activities of glycolytic enzymes in response to endurance training of young rats is modest at best, and some decreases were noted [13]. It was also reported that swimming of old rats increased the aerobic capacity of selected hind limb muscles and increased hexokinase activity [14]. While it is clear, from the reports cited above, that endurance-training of old rats restores enzymatic activities to values close to those in young animals, it was noted in these studies that the activity changes were accompanied by changes in enzyme protein concentrations and hence could reflect a training-associated alteration of cellular protein metabolism. Effects of exercise on the specific activities of these enzymes or on the degree of their alteration by aging have not been studied in detail. The aim of the present investigation was to examine possible effects of long-term endurance training on the status of PGK in muscle tissue of old rats, and to test the hypothesis that aging of this enzyme may be attenuated by the training regimen. 


\section{MATERIALS AND METHODS}

\section{Materials}

The reagents used in PGK preparation, activity assay and treatment were purchased from Sigma Chemical Co. The reagents used for protein assay were purchased from Biorad Laboratories.

\section{Animals}

Female Wistar rats were used in all the experiments of the present work, and were obtained from Charles River Laboratories (Kingston, NY). Rats were housed 2/cage in a $12 \mathrm{~h}: 12 \mathrm{~h}$ light/dark photoperiod, and provided water and food (Purina No. 5008) ad libitum. All procedures were in accord with the guiding principles for the care and use of animals of the American Physiological Society, and had been approved by the University of Michigan Committee on Use and Care of animals.

The old rats $(N=4)$ were studied at 22 months of age, and were obtained at 2 months of age. One-half of the animals lived a cage-sedentary existence, while the others were involved in treadmill running 5 days/week. Treadmill training began at $10 \mathrm{~min} /$ day, $15 \mathrm{~m} / \mathrm{min}, 15 \%$ grade. Speed and duration were increased such that after 1 month the rats ran 5 days/week on a $15 \%$ grade for a total of $70 \mathrm{~min} /$ day: $5 \mathrm{~min}$ at $15 \mathrm{~m} / \mathrm{min}, 60 \mathrm{~min}$ at $30 \mathrm{~m} / \mathrm{min}$, and $5 \mathrm{~min}$ at $15 \mathrm{~m} / \mathrm{min}$. At the time of study, rats were anesthetized with pentobarbital sodium $(35 \mathrm{mg} / \mathrm{kg}$ i.p., supplemental as required). Over the course of $2 \mathrm{~h}$ lower muscles were removed for other purposes (unpublished studies). The heart was excised, the head removed, and the carcass frozen in liquid $\mathrm{N}_{2}$. The carcasses were kept at $-80^{\circ} \mathrm{C}$ for 2 months, at which time the mixed thigh muscles (both knee extensors and flexors) were removed for the present study.

Young animals $(N=9)$ obtained from the same source as the old animals were studied at 4.5 months of age. Three young rats were studied following procedures described in the above paragraph. Since the anesthetic, operation, and subsequent freezing could all affect the properties of the PGK preparations, control experiments were made in which PGK samples were purified from two other groups of young animals $(N=3$ each). In one group, the rats were anesthetized and muscles were removed fresh (within $30 \mathrm{~min}$ ). Rats in the third young group served as experimental controls and were decapitated without anesthetic and the fresh tissue removed for the present study.

\section{PGK isolation}

Skeletal muscle from hind legs was removed and washed in a solution of $20 \mathrm{mM}$ tris-mops buffer ( $\mathrm{pH} 7.0$ ) containing $10 \mathrm{mM}$ 2-mercaptoethanol and $1 \mathrm{mM}$ sodium EDTA. PGK was extracted from the tissue and purified according to the procedure of Sharma et al. [4] as modified by Yuh and Gafni [8].

\section{Protein and enzyme activity assays}

Protein concentrations were determined according to the method of Bradford [15] 
using bovine serum albumin (Sigma) as the standard. PGK activity was assayed at $25^{\circ} \mathrm{C}$ as described by Sharma et al. [4].

\section{Heat inactivation experiments}

These were based on the procedure used in previous studies in our laboratory $[7,8]$. The experiments were conducted at $45^{\circ} \mathrm{C}$ or $47^{\circ} \mathrm{C}$ and were started by adding an aliquot of a concentrated enzyme stock solution (approx. $3 \mathrm{mg} / \mathrm{ml}$ ) into buffer (preheated to the desired temperature) to give a final concentration of PGK of 30 $\mu \mathrm{g} / \mathrm{ml}$. The buffer used contained $70 \mathrm{mM}$ Tris acetate (pH 7.3 or 8.0 ), $35 \mathrm{mM}$ $\mathrm{MgCl}_{2}$ and $10 \mathrm{mM}$ 2-mercaptoethanol. The inactivation reaction was followed by removing $0.1-\mathrm{ml}$ aliquots of enzyme solution at various times, cooling them rapidly on ice and assaying for PGK activity.

\section{Heat inactivation of dialyzed PGK}

To check for possible effects of low molecular weight contaminants on the heat stability of PGK a sample of the enzyme was dialyzed against $5 \mathrm{mM}$ tris-mops buffer (pH 6.7) containing $10 \mathrm{mM}$ 2-mercaptoethanol at $4^{\circ} \mathrm{C}$ for $24 \mathrm{~h}$ with three buffer changes. The dialyzed enzyme was subsequently subjected to heat inactivation as described above.

\section{Correction for basal PGK activity}

A low level of PGK activity was found to be present in the enzyme assay mixture even in absence of added PGK, and probably reflects a contamination (by PGK) in the GPDH used for the assay. This basal activity became a significant fraction of the measured PGK activity in strongly inactivated samples of the latter enzyme. This artifactual activity was corrected for, in the data presented below, by subtracting from each measured activity value the activity of a control assay performed under the same conditions but adding buffer devoid of PGK to the assay mixture.

\section{Unfolding and refolding of PGK}

The enzyme was unfolded by incubation with $2 \mathrm{M} \mathrm{Gdn}: \mathrm{HCl}$ at $4^{\circ} \mathrm{C}$ for $20 \mathrm{~h}$. This treatment has been shown to result in complete unfolding of the enzyme $[8,16,17]$. Following unfolding the PGK was subjected to reactivation by diluting its solution into a 40-fold excess of denaturant-free buffer ( $100 \mathrm{mM}$ sodium phosphate ( $\mathrm{pH} 7.5)$ containing $10 \mathrm{mM}$ 2-mercaptoethanol and $1 \mathrm{mM}$ EDTA) and incubating the solution at $28^{\circ} \mathrm{C}$ for $12 \mathrm{~h}$. The reactivation under these conditions was found to be practically complete (over $95 \%$ of original activity regained). The enzyme solution was then concentrated by use of an Amicon PM-10 membrane to a final concentration of $300 \mu \mathrm{g} / \mathrm{ml}$.

\section{Trypsin-inactivation of $P G K$}

The enzyme was also inactivated irreversibly by treating it with trypsin as describ- 
ed by Rivett [18]. Samples of $30 \mu \mathrm{g} / \mathrm{ml} \mathrm{PGK}$ were incubated at $30^{\circ} \mathrm{C}$ in $50 \mathrm{mM}$ Hepes buffer (pH 7.5) containing $0.25 \mathrm{mM} \mathrm{MgCl} 2,2.5 \mathrm{mM} \mathrm{KCl}, 10 \mu \mathrm{g} / \mathrm{ml}$ trypsin (from Sigma, Type III, 10200 units $/ \mathrm{mg}$ protein) in a total volume of $0.6 \mathrm{ml}$. Aliquots of $0.1 \mathrm{ml}$ of this solution were taken out at various times and assayed for PGK activity.

\section{RESULTS}

Sharma et al. [4] first reported on the occurrence of age-related modifications in rat muscle PGK and observed that while several of the enzyme's properties changed others, including the enzymatic activity, were unaffected by age. Subsequent studies similarly revealed an age-independent activity of PGK in a number of other rat tissues [5-7]. Thus, Hiremath and Rothstein [5] found rat liver PGK to possess both the same specific activity and the same total activity (i.e., units/gtissue) in young and old animals. The data obtained in the present study support these earlier observations. Thus, the PGK activities determined by us were 216 units/g muscle tissue for young rats, 211 units/g for sedentary old rats and 183 units/g tissue for endurance-trained old animals. The enzyme activity, therefore, is only very slightly affected by the rats' age or life style; however, to allow for easier comparison of changes in other properties the data in Figs. $1-5$ are presented as "percent enzymatic activity" (i.e., with the activities normalized to 100 at zero time).

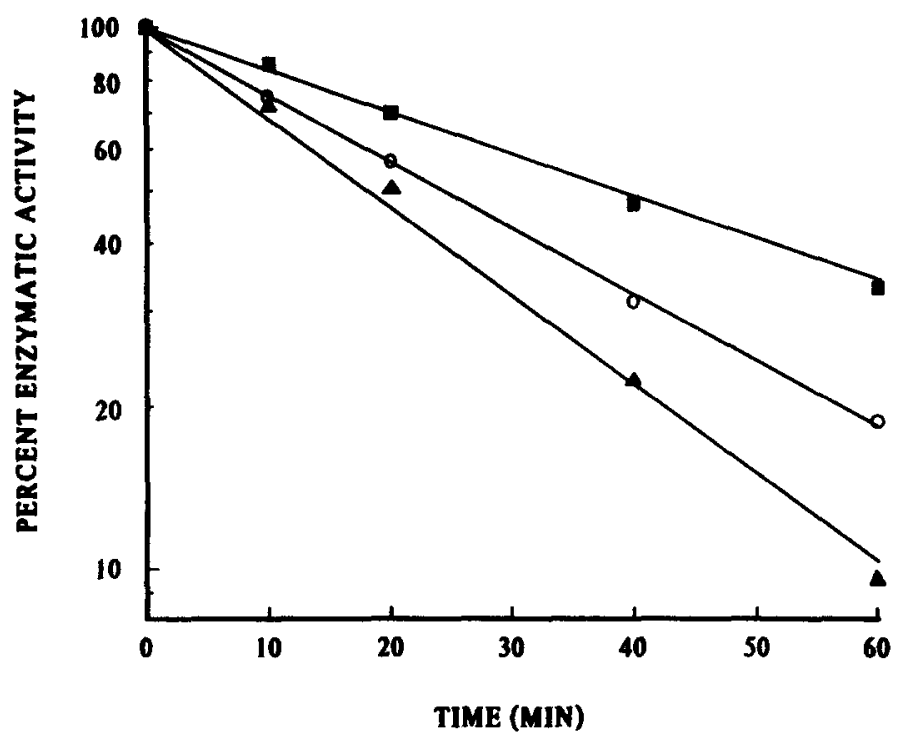

Fig. 1. Heat inactivation kinetics of PGK, purified from the muscle of sedentary old rats, dissolved in a $70 \mathrm{mM}$ Tris acetate buffer containing $35 \mathrm{mM} \mathrm{MgCl} 2$ and $10 \mathrm{mM}$ 2-mercaptoethanol. ( 4 ), pH 8.0, incubation temperature $47^{\circ} \mathrm{C} ;(0) \mathrm{pH} 8.0$, incubation temperature $45^{\circ} \mathrm{C} ;(\mathrm{a}), \mathrm{pH} 7.3$, incubation temperature $47^{\circ} \mathrm{C}$. A more detailed description of the experimental conditions is given under Materials and Methods. 


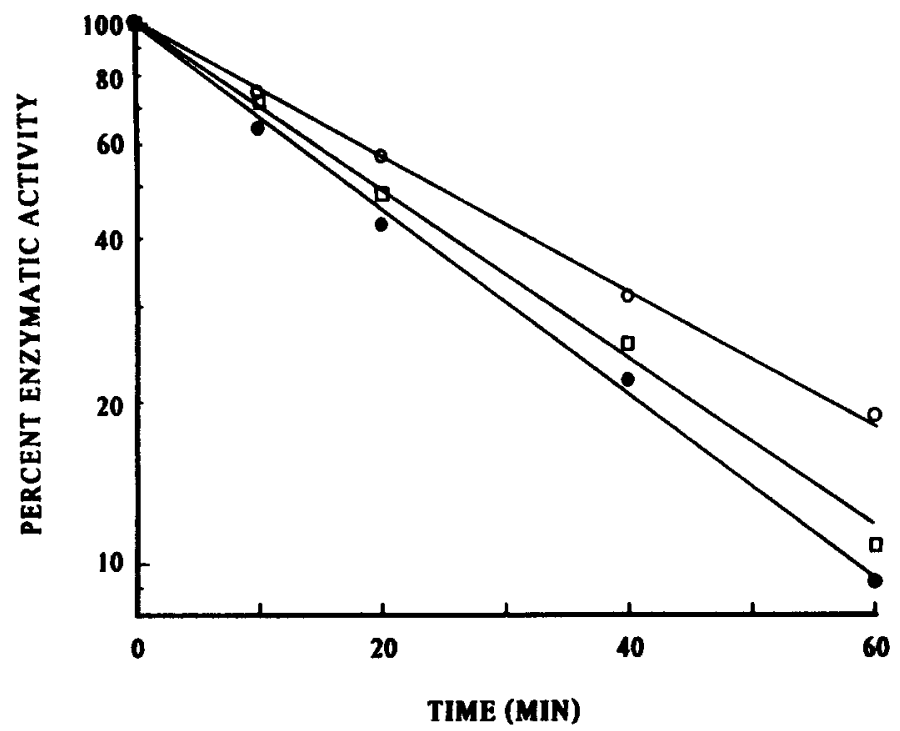

Fig. 2. The kinetics of inactivation of PGK samples isolated from young ( $\square$ ), sedentary old $(0)$ and endurance-trained old $(\bullet)$ rats. Enzyme solutions in $70 \mathrm{mM}$ Tris acetate buffer, pH 8.0, containing 35 $\mathrm{mM} \mathrm{MgCl} 2$ and $10 \mathrm{mM}$ 2-mercaptoethanol were incubated at $45^{\circ} \mathrm{C}$ and their activities assayed as a function of incubation time.

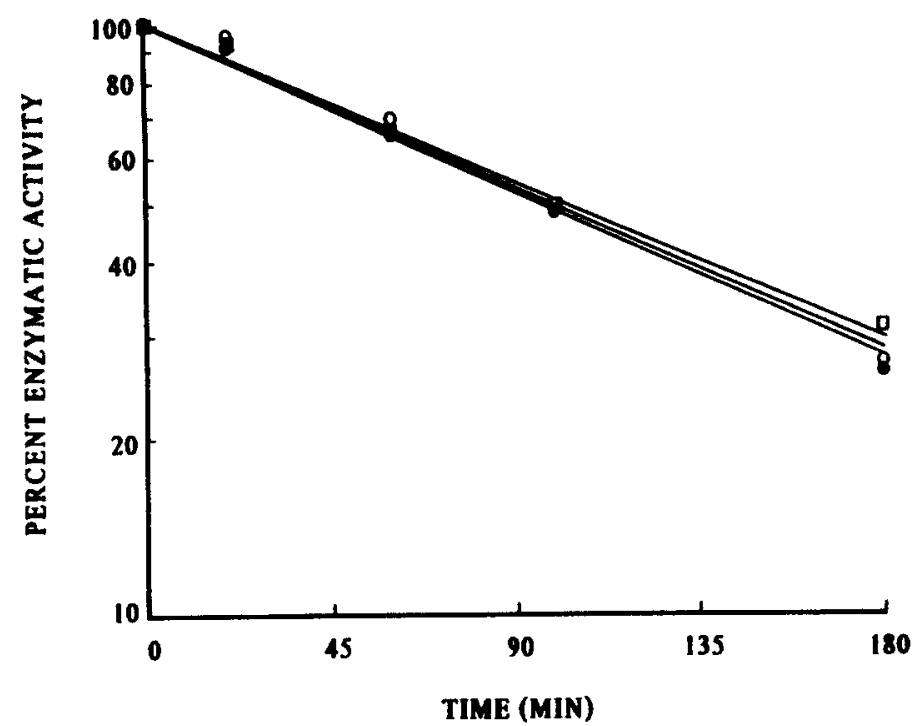

Fig. 3. Trypsin inactivation of samples of PGK isolated from young ( $a$ ), sedentary old $(0)$ and endurance-trained old $(\bullet)$ rats. The enzyme samples were incubated at a concentration of $30 \mu \mathrm{g} / \mathrm{ml}$ in a medium containing $50 \mathrm{mM}$ Hepes buffer, $\mathrm{pH} 7.5,0.25 \mathrm{mM} \mathrm{MgCl}$ and $2.5 \mathrm{mM} \mathrm{KCl}$, at a temperature of $30^{\circ} \mathrm{C}$. Trypsin $(0.02$ units) was added and the activities assayed as a function of time. 


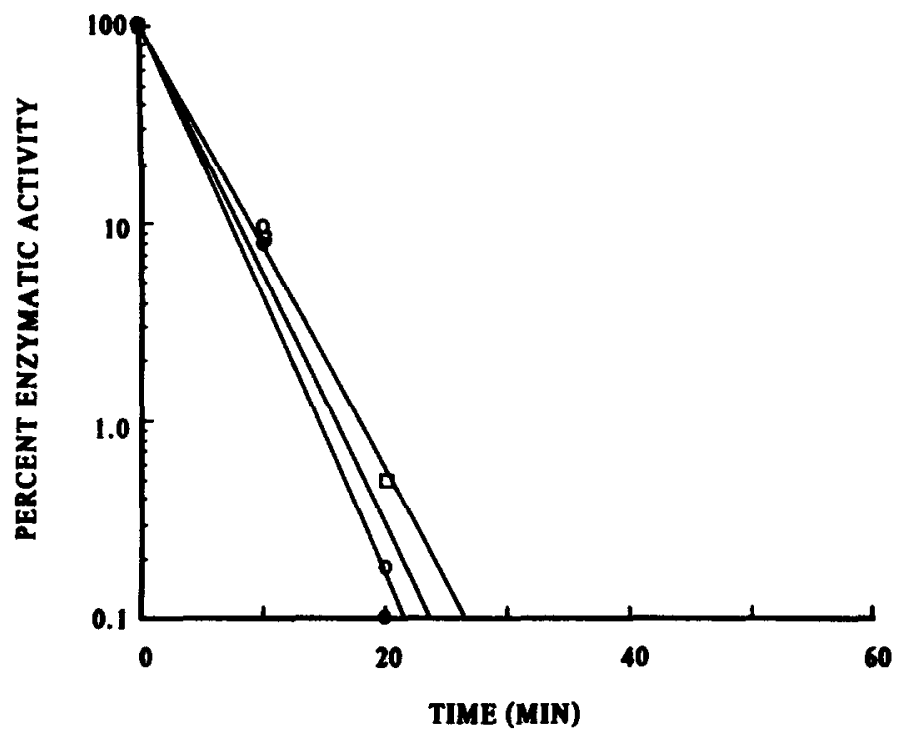

Fig. 4. Heat inactivation kinetics of PGK samples isolated from young $(\square)$, sedentary old $(0)$ and endurance-trained old $(\bullet)$ rats following unfolding-refolding of the protein. Details of the unfoldingrefolding protocol are given under Materials and Methods. The inactivation was performed at $\mathrm{pH} 8.0$ and $45^{\circ} \mathrm{C}$.

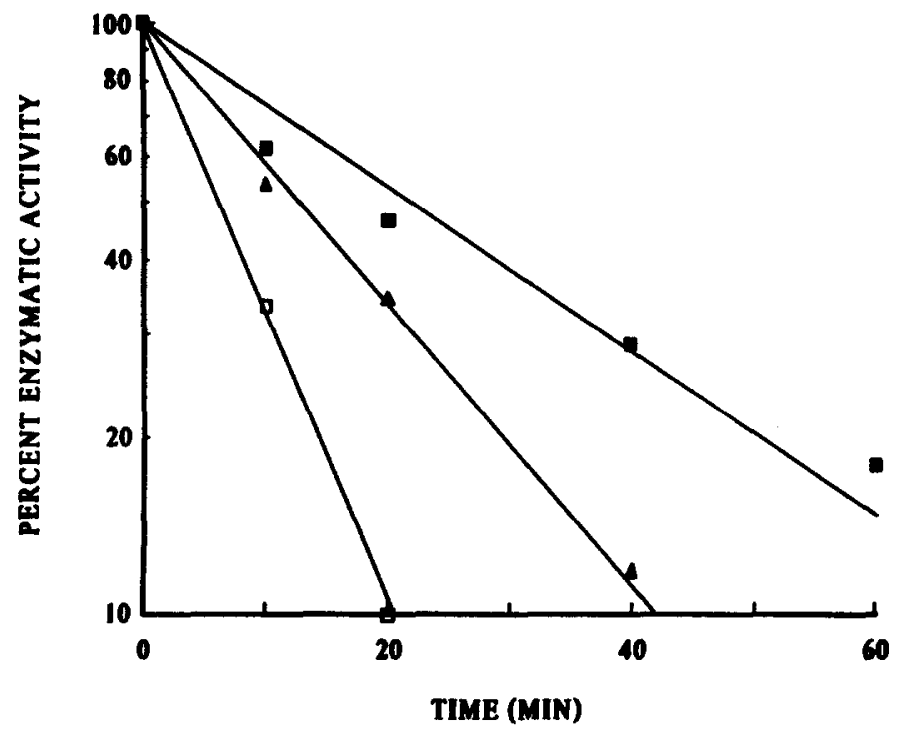

Fig. 5. Effects of animal and muscle tissue treatment on the heat inactivation of the isolated PGK. Young animals were decapitated and muscle tissue collected and immediately used for preparation of PGK ( $\square$ ). Alternatively, animals were anesthesized before decapitation and muscle tissue removed and used immediately $(\Delta)$ or after being stored frozen for 4 weeks $(\square)$. The inactivation was followed at $\mathrm{pH} 8.0$ and $45^{\circ} \mathrm{C}$. 


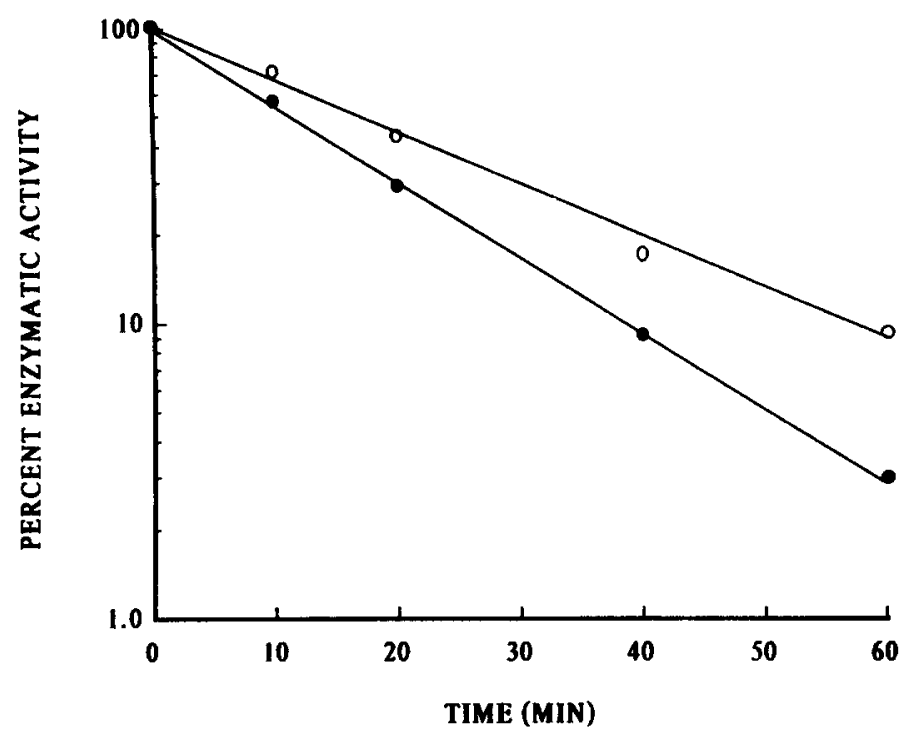

Fig. 6. The heat inactivation kinetics of PGK samples isolated from sedentary old $(0)$ and endurance trained old $(\bullet)$ rats at $\mathrm{pH} 8.0,45^{\circ} \mathrm{C}$, following extensive dialysis of the enzymes.

The rate of heat inactivation of PGK strongly depends on its incubation conditions. The results of several heat inactivation experiments performed under different conditions but all using PGK purified from old, non-exercised, animals are depicted in Fig. 1. While the reaction in all three cases presented follows first order kinetics, the rate of inactivation increases with increasing temperature and is strongly $\mathrm{pH}$ dependent. Thus, the rate constant at $\mathrm{pH} 8.0$ changes from $2.9 \times 10^{-2} \mathrm{~min}^{-1}$ at $45^{\circ} \mathrm{C}$ to $3.6 \times 10^{-2} \mathrm{~min}^{-1}$ at $47^{\circ} \mathrm{C}$, while at the latter temperature and a $\mathrm{pH}$ of 7.3 , the value is only $1.8 \times 10^{-2} \mathrm{~min}^{-1}$. It is worthwhile to note that a marked dependence of PGK inactivation rate on the ionic composition of the incubation medium has previously been documented [7,8]. The employment of identical, well controlled, experimental conditions in comparative studies of PGK forms is, therefore, of utmost importance. Great care was taken in the present study to meet this requirement.

The heat inactivation patterns of PGK isolated from young, old-sedentary and old endurance-trained rats (Y-PGK, OS-PGK and OE-PGK, respectively) all follow first order kinetics (Fig. 2). As has been extensively documented in previous studies [4-8] OS-PGK is more heat stable than Y-PGK. A more striking observation, however, is the great similarity between the heat inactivation kinetics of OE-PGK and Y-PGK, the former enzyme form even being somewhat more heat-labile (Fig. 2). It is significant to note that the inactivation of OE-PGK obeys first-order kinetics down to less than $9 \%$ of the original activity, indicating that the enzyme is homogeneous and does not contain any significant fraction of heat-stable forms. The 
latter would be expected if OE-PGK was a mixture of Y-PGK and OS-PGK. Similarly, the first-order kinetics of the heat inactivation of OS-PGK and of Y-PGK indicate the homogeneity of these samples.

In contrast to the age or training related alterations in the heat stability of PGK, no differences were observed when comparing the rates of inactivation of the three PGK forms by trypsin (Fig. 3). This indicates that the accessibility of basic amino acid residues of PGK to this proteolytic enzyme is not significantly modified by age or by endurance-exercise. The results also show that the inactivation by proteolysis, like heat inactivation, follows first order kinetics (down to below $30 \%$ of the original activity). It is interesting to note that Sharma and Rothstein who used a protease from Streptomyces griseus to inactivate rat brain PGK found the young enzyme to be more labile than its old counterpart [6]. Whether the difference between the results of these authors and the ones presented here reflects differences between muscle and brain PGKs or is due to different selectivities of the two proteolytic enzymes used is not known.

The heat inactivation patterns of Y-PGK, OS-PGK and OE-PGK samples which have been extensively unfolded in $2 \mathrm{M} \mathrm{Gu}: \mathrm{HCl}$ and then refolded to regain full enzymatic activity are depicted in Fig. 4. Two important points to note are the great similarity in the inactivation rates of all three enzyme forms, and the marked increase in the heat lability of each of these enzymes following the unfolding-refolding protocol. Thus, the rate constant for inactivation of OS-PGK increased about ninefold from a value of $2.9 \times 10^{-2} \mathrm{~min}^{-1}$ before unfolding-refolding to $25 \times 10^{-2} \mathrm{~min}^{-1}$ following this procedure, while the rate for Y-PGK increased about sixfold. This latter increase is at odds with previous findings where native and unfolded-refolded $Y$ PGKs displayed similar heat inactivation kinetics [7-9]. Also the enzyme form obtained from either Y-PGK or OS-PGK following unfolding-refolding has been previously shown to be identical to the native (untreated) young enzyme while in the present study the unfolded-refolded enzymes were significantly more heat-labile than the native Y-PGK (cf. Figs. 2 and 4). This could be the result of the introduction of some modifications into the enzyme during its purification. The only difference between PGK preparation in the present study and the studies cited above was the procedure used in the sacrifice of animals, i.e. the anesthesia and operation used here could possibly affect the animals (stress) in a way that would be reflected in the PGK. To test this possibility we isolated PGK samples from tissue of young rats belonging to three groups as detailed in Materials and Methods: (1) anesthetized and frozen tissue; (2) anesthetized and fresh tissue; and (3) no anesthetic and fresh tissue (however, freezing the latter tissue for up to 12 months has no effect on PGK [4]). PGK purified from each of these three groups was then subjected to heat inactivation and the results, presented in Fig. 5, show a remarkable effect of animals and tissue treatment on the enzyme's stability. PGK from group-one animals is considerably more stable than enzyme from group-three animals, the latter enzyme showing heat inactivation rate approaching (though not identical to) those of the unfolded- 
refolded enzymes shown in Fig. 4. It is, however, important to note that the group differences due to exercise training, are not compromised by these experimental concerns, as all tissues in each experimental group were treated similarly.

Why the experimental procedure used in animals treatment has such a profound effect on the enzymes heat stability is not clear. The heat stabilization is, however, fully reversible (since the unfolded-refolded PGK is again heat labile) and is thus very unlikely to reflect a covalent modification of the enzyme. We therefore tested the possibility that this stabilization is due to the binding of a low molecular weight ligand which is removed upon enzyme unfolding. The experiment involved extensive dialysis of OS-PGK and OE-PGK followed by heat inactivation. The results, depicted in Fig. 6 closely resemble those shown in Fig. 3, which have been obtained without dialysis, and reveal no effect of the latter treatment on the heat inactivation rates. It thus appears that a non-covalent binding of a ligand cannot explain the stabilization of PGK and that this effect is best explained in terms of some conformational modification in the enzyme which augments the ones described in our previous reports [7-9].

\section{DISCUSSION}

Effects of long-term endurance training on muscle physiology and biochemistry have been documented and studied in some detail, and changes in the activities of several glycolytic and mitochondrial enzymes have been reported [11-14]. Agerelated declines in various properties of mammalian muscles have also been well documented, and include reduction in mass [23], force [24], rate of contraction [25], as well as in the activities of a variety of enzymes [1-3,12-21]. Endurance-training was reported to induce an enzymatic adaptation in old rat muscle, bringing the activities closer to their respective values in young muscle [12]. These activity changes have been attributed to alterations with training in the amounts of the corresponding enzymes. They may, however, be the manifestation of exercise-induced effects at the molecular level (i.e. changes in the structures and specific activities of these muscle proteins). This interesting possibility has not been addressed in previous studies, and was the theme of the present investigation. PGK was chosen for this study since this glycolytic enzyme is easily purified in good yield and because the effects of aging on it have been characterized and studied in great detail $[4-6,22]$. Moreover, the aging effects in PGK have been recently shown to be the result of conformational modifications only, and can be reversed by taking the enzyme through an unfoldingrefolding cycle [7--8]. More recently the involvement of reactive cysteine residues in the aging process of PGK has been demonstrated in experiments where young PGK was protected against in vitro aging by selective partial methylation of these amino acid residues [9]. One of the most prominent age-related effects in PGK is the increase in the heat stability of the enzyme [4]. This parameter, which served in many of the previous studies cited above was also utilized in the present investigation as a probe for the status of the enzyme. 
The major finding of the present study is that PGK isolated from the muscle of old rats, which have been subjected to long-term endurance training, shows a remarkable similarity in its heat inactivation kinetics to PGK purified from young animals, and is significantly different from the enzyme obtained from sedentary old animals. Since the heat inactivation kinetics of PGK is a sensitive measure of the enzyme status we conclude that the remarkable effects of long-term endurance training on the intrinsic properties of PGK, reported here, demonstrate that trainirig does have an outcome at the molecular level as manifested in enzymatic properties.

The conclusion reached in previous studies that the age-related structural modifications in PGK are purely conformational $[7,8,22]$ is corroborated by the present demonstration that Y-PGK, OS-PGK and OE-PGK all display an identical heat inactivation pattern following unfolding-refolding (a treatment which is unlikely to abolish any covalent modifications in the enzyme). The mechanism for PGK aging which has been proposed [9] involves an initial oxidation of reactive cysteine residues, followed by conformational modifications which are not reversed upon enzyme reduction and reactivation. The prevalence of this modified form of PGK in old tissues may be due to a longer dwell time for the enzyme in old cells, as proposed by Rothstein [1,2], or be a result of the documented age-related increase in the oxidation potential of muscle [26]. The latter would enhance the rate of PGK modification so as to make this process effective even when no changes are present in its dwelltime in the cell. The endurance-training may thus influence the status of PGK in old rat muscle either by increasing the rate of protein turnover, or by shifting the redox potential towards a value closer to the one found in young tissue. Which of these two mechanisms is responsible for the effects observed in the present study is not clear; however, the fact that the activities of several other enzymes have also been reported to become partially restored by endurance-training [11,12] provides some indication that a general mechanism is operating here. This would be more compatible with the explanation based on an increased rate of protein turnover than with the reduced-oxidation mechanism since this latter mechanism may be expected to affect only proteins which are particularly sensitive to small changes in the redox potential. For PGK, a demonstration that the modifications involved in aging can occur relatively rapidly (on a time scale shorter than the enzymes turn-over time in the cell) is provided by our observation that the use of anesthesia and surgery before the animals killing results in a marked increase in the heat stability of PGK. Moreover this effect is further augmented by freezing the tissue before enzyme isolation. In this context it is interesting to note that storing frozen muscle tissue from unanesthetized rats for periods as long as 1 year had no effect on the heat stability of PGK [4]. The reason for the observed changes in PGK as a result of animal handling, is not clear. As in aging, the activity of the enzyme was not affected by this treatment and its increased heat stability disappeared following unfolding-refolding. It is unlikely that the latter observation is the result of the dissociation of a low molecular weight ligand since even extensive dialysis did not lead to any significant modulation in the heat inactivation pattern. 
The effect of long-term endurance training on the status of PGK from old rats is remarkable. Indeed this enzyme shows heat inactivation rates at least as high as young PGK. To the best of our knowledge this is the first demonstration of the effects of exercise on enzymatic properties at the molecular level. The cellular origin of the effect and how other enzymes respond to training is left for future studies.

\section{ACKNOWLEDGEMENT5}

This research was supported by National Institutes of Health Grant AG-06130 (to T.P.W.), and by grants from the Office of Naval Research and from the W.K. Kellogg Foundation (to A.G.). The authors thank Kathy Gilbert for animal training and Kris Daw for technical support.

\section{REFERENCES}

1 M. Rothstein, Biochemical Approaches to Aging. Academic Press, London, 1983.

2 M. Rothstein, The alteration of enzymes in aging. Mod. Aging Res., 7 (1985) 53-67.

3 E.R. Stadtman, Protein modification in aging. J. Gerontol, 43 (1988) B112-120.

4 H.K. Sharma, H.R. Prasanna and M. Rothstein, Altered phosphoglycerate kinase in aging rats. $J$. Biol. Chem., 255 (1980) 5043-5050.

5 L.S. Hiremath and $M$. Rothstein, The effect of aging on rat liver phosphoglycerate kinase and comparison with the muscle enzyme. Biochim Biophys. Acta, 705 (1982) 200-209.

6 H.K Sharma and M. Rothstein, Altered brain phosphoglycerate kinase from aging rats. Mech. Ageing. Dev., 25 (1984) 285-296.

7 A. Zuniga and A. Gafni, Age-related modifications in rat cardiac phosphoglycerate kinase. Rejuvenation of the old enzyme by unfolding-refolding. Biochim. Biophys. Acta, 955(1988) 50-57.

8 K.C.M. Yuh and A. Gafni, Reversal of age-related effects in rat muscle phosphoglycerate kinase. Proc. Natl. Acad. Sci. USA, 84 (1987) 7458-7462.

9 L.L. Cook and A. Gafni, Protection of phosphoglycerate kinase against in vitro aging by selective cysteine methylation. J. Biol. Chem., 263 (1988) 13991-13993.

10 J.A. Faulkner and T.P. White, Adaptations of skeletal muscle to physical activity. In C. Bouchard (ed.), Exercise. Fitness and Health, Human Kinetics Champaign, 111., 1990, pp. 265-279.

11 J.O. Holloszy and F.W. Booth, Biochemical adaptations to endurance exercise in muscle. Annu. Rev. Physiol., 38 (1976) 273-291.

12 J. Sanchez, C. Bastien and H. Monod, Enzymatic adaptations to treadmill training in skeletal muscle of young and old rats. Eur. J. Appl. Physiol., 52 (1983) 69-74.

13 K.M. Baldwin, W.W. Winder, R.L. Terjung and J.O. Holloszy, Glycolytic enzymes in different types of skeletal muscle: Adaptation to exercise. Am. J. Physiol., 225 (1973) 962-966.

14 H. Klitgaard, A. Brunet, B. Maton, C. Lamaziere, C. Lesty and H. Monod, Morphological and biochemical changes in old rat muscles: Effect of increased use. J. Appl. Physiol., 67 (1989) 1409-1417.

$15 \mathrm{M}$. Bradford, A rapid and sensitive method for quantitation of microgram quantities of protein utilizing the principle of protein-dye binding. Anal. Biochem, 72 (1976) 248-254.

16 M. Desmadril, A. Mitraki, J.M. Betton, and J.M. Yon, $\mathrm{GuHCl}$ induced unfolding-folding transition of a hinge-bending protein: Horse muscle phosphoglycerate kinase. Biochem. Biophys. Res. Commun., 118 (1984) $416-422$.

17 J.M. Betton, M. Desmadril, A. Mitraki, and J.M. Yon, Kinetic studies of the unfolding-refolding of horse-muscle phosphoglycerate kinase induced by guanidine hydrochloride. Biochemistry, 24 (1985) $4570-4577$.

18 A.J. Rivett, Preferential degradation of the oxidatively modified form of glutamine synthetase by intracellular mammalian proteases. J. Biol. Chem., 260 (1985) 300-305. 
19 A. Gafni, Age-related modifications in a muscle enzyme. In R.C. Adelman and E.E. Dekker (eds.), Modifications of Proteins During Aging, Alan R. Liss, New York, 1985, pp. 19-38.

20 A. Gafni and N. Noy, Age-related effects in enzyme catalysis. Mol. Cell. Biochem., 59 (1984) $113-129$.

21 A. Gafni, Altered protein metabolism in aging. Ann. Rev. Gerontol. Geriat., 10 (1990) 117.

22 H. Hardt and M. Rothstein, Altered phosphoglycerate kinase from old rat muscle shows no change in primary structure. Mech. Ageing Dev., 25 (1984) 285-296.

23 G. Grimby and B. Saltin, The aging muscle. Clin. Physiol. Oxf., 3 (1983) 209-218.

24 C.T.M. Davies, M.J. White and K. Young, Electrically evoked and voluntary maximal isometric tension in relation to dynamic muscle performance in elderly male subjects aged 69 years. Eur. J. Appl. Physiol. Occup. Physiol., 51 (1983) 37-43.

25 I. Syrovy and E. Gutmann, Changes in speed of contraction and ATPase activity in striated muscle during old age. Exp. Gerontol., 5 (1970) 31-35.

26 N. Noy, H. Schwartz and A. Gafni, Age-related changes in the redox status of rat muscle cells and their role in enzyme aging. Mech. Ageing Dev., 29 (1985) 63-69. 